Tropical Journal of Pharmaceutical Research November 2015; 14 (11): 1953-1960

ISSN: $1596-5996$ (print); 1596-9827 (electronic)

(C) Pharmacotherapy Group, Faculty of Pharmacy, University of Benin, Benin City, 300001 Nigeria.

All rights reserved.

Available online at http://www.tjpr.org

Original Research Article

http://dx.doi.org/10.4314/tjpr.v14i11.1

\title{
Process and Kinetic Mechanism of Elimination of Chlorine Combined in Molecule of Bleached Shellac
}

\author{
Yalong Liao*, Juan Zhou and Feirong Huang \\ Faculty of Metallurgical and Energy engineering Kunming University of Science and Technology, Kunming 650093, China
}

*For correspondence: Email: liaoylsy@163.com; Tel.: +86-871-65198154; Fax: +86-871-65198154

Received: 7 January 2015

Revised accepted: 3 October 2015

\begin{abstract}
Purpose: To investigate the process and kinetics of the removal of chlorine integrated in a molecule of bleached shellac applied as pharmaceutical excipient.

Methods: Sodium ethoxide was employed to react selectively with the carbon atom connecting with chlorine, which induced the removal of chlorine by means of elimination reaction. The technologic parameters, such as dosage of sodium ethoxide, temperature, time, etc, influencing dechlorination efficiency were studied. Furthermore, the kinetics of chlorine removal was investigated by analyzing the variation of chlorine content with time and temperature.

Results: The results demonstrate that the optimal conditions for eliminating combined chlorine are to react with $3.15 \mathrm{~g}$ of sodium ethoxide at $90{ }^{\circ} \mathrm{C}$ for $90 \mathrm{~min}$. Under the optimal conditions, the content of chlorine in the final products is $0.28 \% \mathrm{w} / \mathrm{w}$, which is far smaller than that in the products prepared without dechlorination $(2.6 \% \mathrm{w} / \mathrm{w})$..

Conclusion: Combined chlorine, which is harmful to the properties of shellac, can be removed in the presence of sodium ethoxide by means of elimination, and the reaction for chlorine content of shellac is first order reaction.
\end{abstract}

Keywords: Enteric coating, Sustained release, Elimination method, Nucleophile, Shellac, Natural products

Tropical Journal of Pharmaceutical Research is indexed by Science Citation Index (SciSearch), Scopus, International Pharmaceutical Abstract, Chemical Abstracts, Embase, Index Copernicus, EBSCO, African Index Medicus, JournalSeek, Journal Citation Reports/Science Edition, Directory of Open Access Journals (DOAJ), African Journal Online, Bioline International, Open-J-Gate and Pharmacy Abstracts

\section{INTRODUCTION}

Shellac is a purified product of the natural material originally secreted by the lac insect, which parasitically grows on some types of tree in Southeast Asian [1]. Because of many outstanding properties, such as non-toxicity, nonirritating, excellent film forming, good acidresistibility, etc., it is generally recognized as safe by the food and drug administration (FDA) [2]. Therefore, shellac is intensively applied as an additive in food products, where it has already played a major role as coating for confectionaries, fruits refreshing [3-7] and food field [8-10], after refining with sodium hypochlorite to remove residues such as Lac pigment and Lac wax associated with shellac. The shellac resin is also widely employed in the pharmaceutical industry [11-14]. It can develop the dosage of a drug released in forms of sustained and/or site specific means while shellac is used as enteric film polymers of drug [15-17]. However, in the bleaching process for refining shellac, chlorine is added to the double bonds of shellac molecular structure, and combined chlorine is formed in the final products. The chlorine integrated can accelerate the polymerization among the intermolecular bonds of shellac, which results in a poor storage performance and bad physical chemistry 
properties [18]. In fact, the shelf life of shellac products is less than a half year, and the existence of chlorine contained in shellac confines its intensive application in the pharmaceutical and food industry.

Due to some differences in the composition and structure of seedlac used for refining shellac [19], the parameters controlling the bleaching process are protected as know-how by manufacturers, so the chlorine amount in bleached shellac varies significantly in different products. The chlorine content of bleached shellac prepared by some manufacturers in China is higher than that of the products obtained by importation, and it is much higher than that of products required for food and pharmaceuticals. Some articles touching upon how to eliminate the chlorine combined in shellac have been documented. WANG DX [20] obtained shellac with a chlorine amount of $0.63 \% \mathrm{w} / \mathrm{w}$ and investigated the mechanism of chlorine removal in bleached solution, in which shellac was modified with sodium hypochlorite. However, the methodology on the preparation and the chemical agents conducted in the process has not been reported yet. Liao et al [21-23] prepared shellac with chlorine content less than $0.5 \% \mathrm{w} / \mathrm{w}$ by adding binary metal catalysts with $\mathrm{Pd}$ and/or $\mathrm{Ni}$ as active ingredients. When reacting with hydrogen, the chlorine integrated in the products is substituted by hydrogen in the presence of the binary metal catalysts by means of catalytic hydrogenation.

The objective of this work was to remove the chlorine integrated in shellac molecule during the process of bleaching. Sodium ethoxide mixed with ethanol which was performed as a nucleophilic agent was put in to remove the binding chlorine in the bleached solutions in which shellac was modified with sodium hypochlorite. The influencing factors, such as the type of nucleophilic agents, reaction time and reaction temperature, which affected the efficiency of chlorine removal were investigated. Also, the kinetics of eliminating the integrated chlorine was studied.

\section{EXPERIMENTAL}

\section{Material and instruments}

The materials used in this work were anhydrous ethanol of $95 \% \mathrm{v} / \mathrm{v}(\mathrm{AR})$, sodium ethoxide (AR), sodium carbonate (AR), sulfuric acid (AR), sodium hypochlorite (Industrial grade) and seedlac. Apart from sodium hypochlorite which was purchased from Yunnan salt \& salt chemical
Co., Ltd. China and seedlac from Yunnan Mojiang Hongsen Special Agriculture Co., Ltd. China, the others were purchased from Sinopharm chemical reagent Co, Ltd. The lowtemp circulator bath (DLSB-5/10) and water recycling vacuum pump (SHZ-DIII) were purchased from Gongyi Yuhua Instruments Co, Ltd, China.

\section{General procedure}

$50 \mathrm{~g}$ of seedlac was dissolved in $250 \mathrm{~mL}$ solution with a content of sodium carbonate $5 \% \mathrm{w} / \mathrm{w}$ at $90{ }^{\circ} \mathrm{C}$ for $30 \mathrm{~min}$. Seedlac alkaline solution was obtained after the branches, insects and other impurities contained in seedlac were filtered using stainless steel sieve. It was bleached using sodium hypochlorite solution with an effective chlorine concentration of $3 \% \mathrm{w} / \mathrm{w}$ when the temperature of seedlac alkaline solution was cooled down at $40^{\circ} \mathrm{C}$. After the color index of the bleaching solution reached 1.2 (Gardner color index), the process was stopped. Then two procedures were employed to process the bleached solution. Method A: it was treated by adding dilute sulfuric acid to precipitate the resin, and bleached shellac was prepared after the resin was consecutively filtered, washed and dried. Method B: it was processed to eliminate chlorine at specified temperature for different times by adding the mixture of sodium ethoxide and ethanol to remove the chlorine integrated in the molecule. After the dechlorination process was fulfilled, the temperature of the reactant was lowered down to $30^{\circ} \mathrm{C}$, and then dilute sulfuric acid was put in to deposit the resin. In the end, the bleached shellac with low chlorine content was obtained by filtering, washing and drying the precipitation.

\section{Effect of dechlorination agent}

Bleached solution with volume of $600 \mathrm{~mL}$ was treated by different methods. For the first method, the mixture of sodium ethoxide and 30 $\mathrm{mL}$ of ethanol were acceded to the solution; considering the second method, $30 \mathrm{~mL}$ of ethanol was added; and the other method was conducted without these materials. These solutions were respectively stirred for $90 \mathrm{~min}$ at different temperatures. Then diluted sulfuric acid was put in to deposit resin. Consequently the precipitation was separated by vacuum filtration and washed using deionized water until the filtration was neutral. Then the precipitation was dried in the oven to obtain final products of shellac. At the end, the content of chlorine in the products was tested. 


\section{Effect of amount of sodium ethoxide on chlorine content}

Several bleached solutions with volume of 600 $\mathrm{mL}$ were taken, and each was added with the mixture of $30 \mathrm{~mL}$ of ethanol that dissolved with sodium ethoxide to react for $90 \mathrm{~min}$ at ambient temperature, $40,50,60,70,80$ and $90{ }^{\circ} \mathrm{C}$. The amounts of sodium ethoxide were $0,0.45,0.90$, $1.35,1.80,2.25,2.70,3.15,3.60$, and $4.05 \mathrm{~g}$, respectively. Thereafter, $5 \% \mathrm{w} / \mathrm{w}$ of diluted sulfuric acid was added to deposit resin. Afterwards, the precipitation was separated by vacuum filtration and washed using deionized water until the filtration was neutral.

Then the precipitation was dried in an oven to acquire the final products of shellac. At the end, the amount of chlorine in the products was tested to investigate the effects of amount of sodium exthoxide on dechlorination.

\section{Effect of reaction temperature on chlorine content of products and dechlorination efficiency}

Several bleached solutions with volume of 600 $\mathrm{mL}$ were taken, each of which was added with the mixture of $30 \mathrm{~mL}$ of ethanol dissolved with $3.15 \mathrm{~g}$ of sodium ethoxide, to react for $90 \mathrm{~min}$ at different temperatures. Then diluted sulfuric acid was put in to deposit resin, and the precipitation was separated by vacuum filtration and washed using deionized water until the filtration was neutral. Then the precipitation was dried in the oven to get final products of shellac. At the end, the content of chlorine in the products was tested to explore the effects of reaction temperature on dechlorination.

\section{Effect of reaction time on chlorine content}

Several $4,800 \mathrm{~mL}$ of bleached solutions were taken. Each solution was added with the mixture of $240 \mathrm{~mL}$ of ethanol dissolved with $25.20 \mathrm{~g}$ of sodium ethoxide, to react for a specified time at $50,60,70,80$, and $90^{\circ} \mathrm{C}$, respectively. During the reaction, samples were taken respectively at $10,20,30,40,50,60,70,80$ and $90 \mathrm{~min}$ for precipitating resin with diluted sulfuric acid when they were cooled down to ambient temperature.

Then the precipitation was separated by vacuum filtration and washed using deionized water until the filtration was neutral. Afterwards, they were dried in the oven to obtain the final products of shellac. At the end, the amount of chlorine in the products was tested to study the effects of reaction time on chlorine content.

\section{Detection method}

The chlorine content of the products was tested according to Lac products-testing methods GB/T8143-2008. Chlorine in the sample was converted to soluble chloride by sodium, and then quantitative silver nitrate and ammonium ferric sulfate were added to precipitate the chlorine ion in the acidic conditions. Afterwards, potassium sulfocyanate was used to titrate the consumption of silver nitrate for calculating the chlorine content in the samples. The chlorine content of the samples could be calculated as in Eq 1.

$X=\left\{\left[\left(V_{0}-V\right) \times C \times 0.03546\right] / m\right\} \times 100 \ldots \ldots$.

where: $\mathrm{X}$ - chlorine content in sample, $\% \mathrm{w} / \mathrm{w} ; \mathrm{V}_{0}$ - volume of potassium sulfocyanate consumed in vacant conditions, $\mathrm{mL}$; $\mathrm{V}$ - volume of potassium sulfocyanate consumed in sample tested conditions, $\mathrm{mL}$; $\mathrm{C}$ - the accurate concentration of potassium sulfocyanate, $\mathrm{mol} / \mathrm{L} ; \mathrm{m}$ - the mass of sample, g; 0.03546 - the mass equivalent to chlorine of per millimole potassium sulfocyanate, $\mathrm{g} / \mathrm{mmol}$.

\section{RESULTS}

\section{Effect of dechlorination agent}

The effect of the nature of the dechlorination agent on chlorine content was shown in Figure 1. It could be verified from Figure 1 that the nature of the dechlorination agent played a pivotal role in the chlorine amount in shellac products. Owing to none of dechlorination agent was put into the bleached solution, the chlorine content decreased to some extent when the reaction temperature increased by $50{ }^{\circ} \mathrm{C}$ from $40{ }^{\circ} \mathrm{C}$. However, the decrease of chlorine was negligible as the temperature rose and exceeded $50{ }^{\circ} \mathrm{C}$. It also could be found that when ethanol was added as the dechlorination agent, the variation between the chlorine content of the products and the reaction temperature was nearly the same as that without dechlorination agents. Even though the chlorine content of the products decreased to some extent by applying ethanol as the chlorine elimination agent, the products obtained cannot be applied in the pharmaceutical area. This is because the chlorine amount is much higher than that of the products that could be tolerated in this domain. While, as reaction temperature increased, the chlorine content of the products sharply decreased with the presence of sodium ethoxide in the bleached solution, which was agitated for $90 \mathrm{~min}$ at $90{ }^{\circ} \mathrm{C}$. 


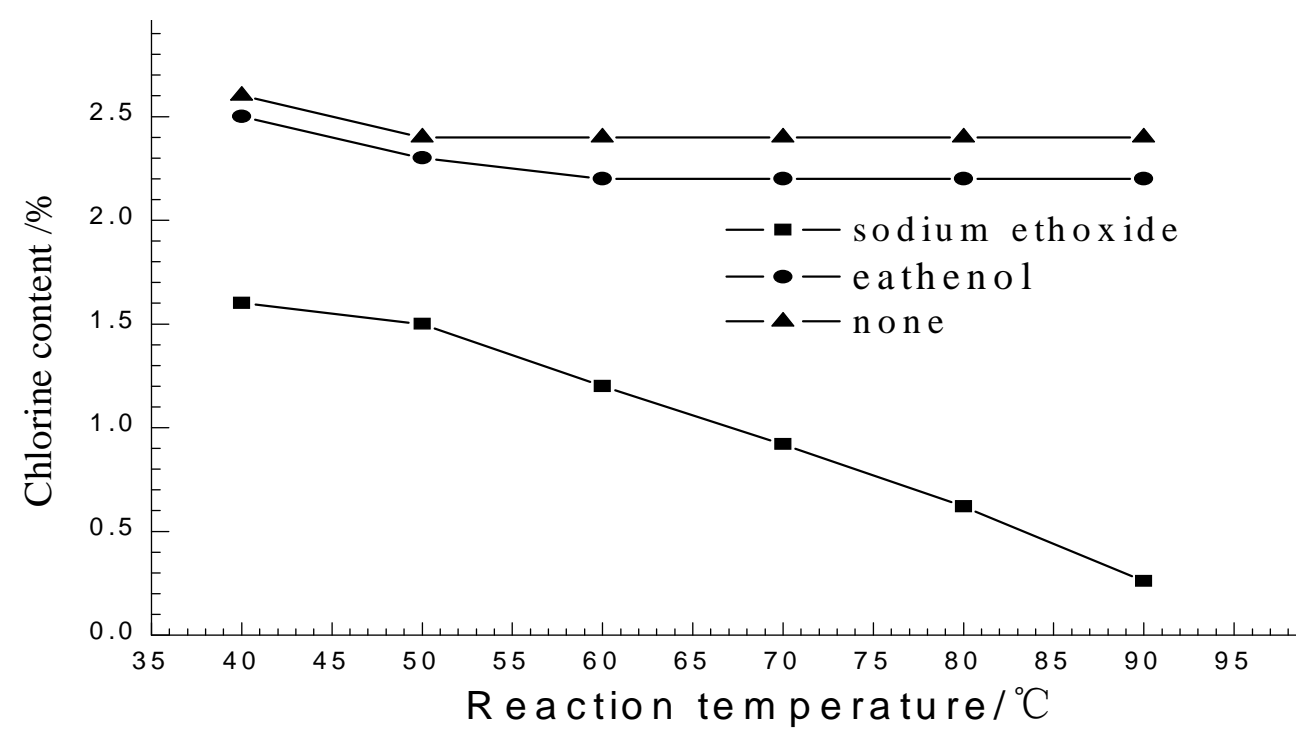

Figure 1: Effect of the nature of the dechlorination reagent on the chlorine content

\section{Effect of amount of sodium ethoxide on chlorine content}

The effects of the amount of sodium ethoxide, which was adopted as dechlorination agent, on the chlorine content of products at different temperatures were indicated in Figure 2.

It was observed from Figure 2 that at ambient temperature, the amount of sodium ethoxide employed in the dechlorination reaction showed little effect on the dechlorination efficiency. It is proved by the fact that the chlorine amount in shellac is the same value $2.60 \% \mathrm{w} / \mathrm{w}$ as that of the products that were manufactured without dechlorination agents. The amount of sodium ethoxide applied in dechlorination reaction played a significant role in the efficiency of chlorine elimination, when the reaction temperature increased. With the increase of the consumption amount of sodium ethoxide, the chlorine content of the products was decreased effectively. Slight advantages of sodium ethoxide for eliminating chlorine amount in the products could be fulfilled while its amount exceeded 3.15 $\mathrm{g}$, as illustrated in Figure 2. Therefore, the optimum amount of sodium ethoxide was $3.15 \mathrm{~g}$.

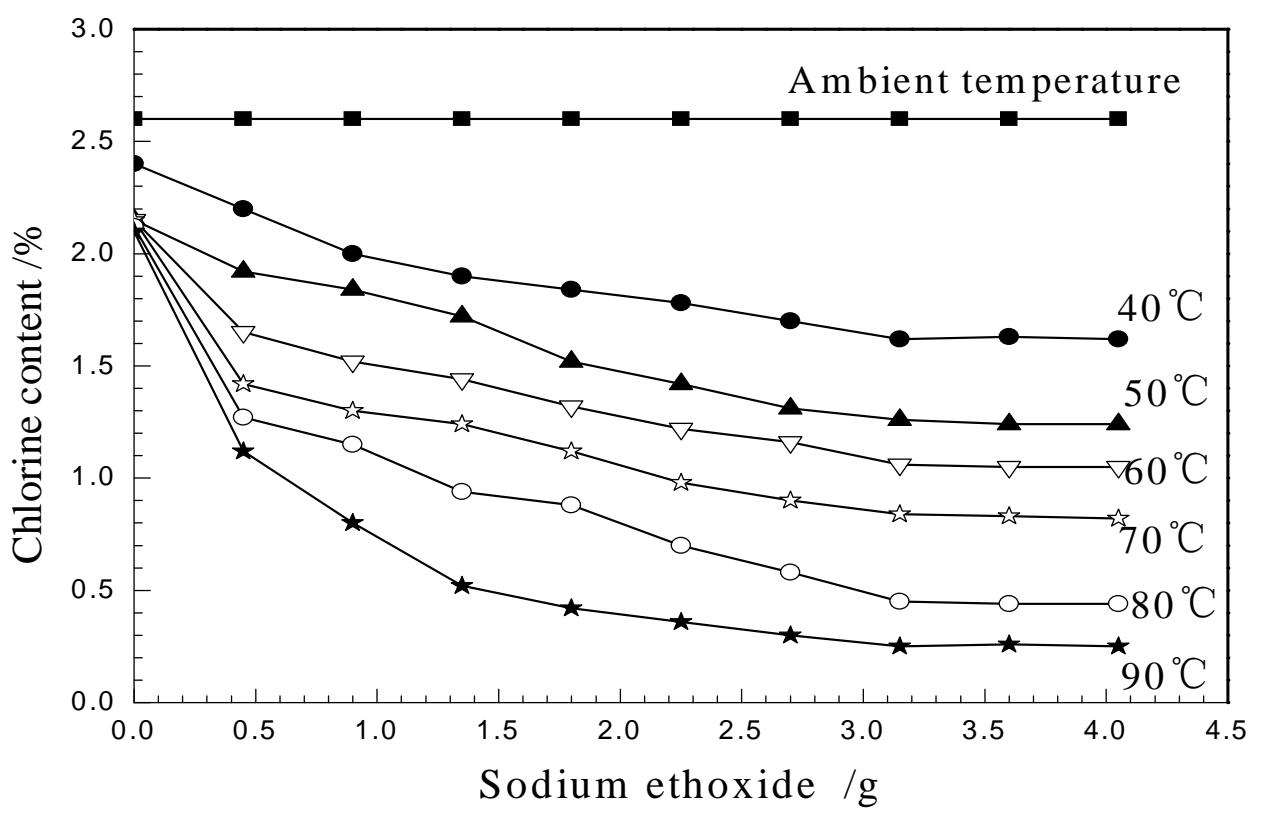

Figure 2: Effect of amount of sodium ethoxide on chlorine content 
Effect of reaction temperature on chlorine content and dechlorination efficiency

The effects of temperature on chlorine content of products and dechlorination efficiency were presented in Figure 3.

It could be found from Figure 3 that reaction temperature played a vital role in dechlorination. With the increase of reaction temperature, the chlorine amount in final products decreased sharply and most of chlorine integrated in the bleaching modification process was eliminated.
As the dechlorination reaction were undergone at $70{ }^{\circ} \mathrm{C}$, the chlorine content in the products could be reduced to the value of $1.0 \% \mathrm{w} / \mathrm{w}$, while the chlorine content was $0.28 \% \mathrm{w} / \mathrm{w}$ when the dechlorination reaction were carried out at $90{ }^{\circ} \mathrm{C}$.

Effect of reaction time on chlorine content of products

The variations of chlorine content with reaction time at different reaction temperatures were expressed in Figure 4.

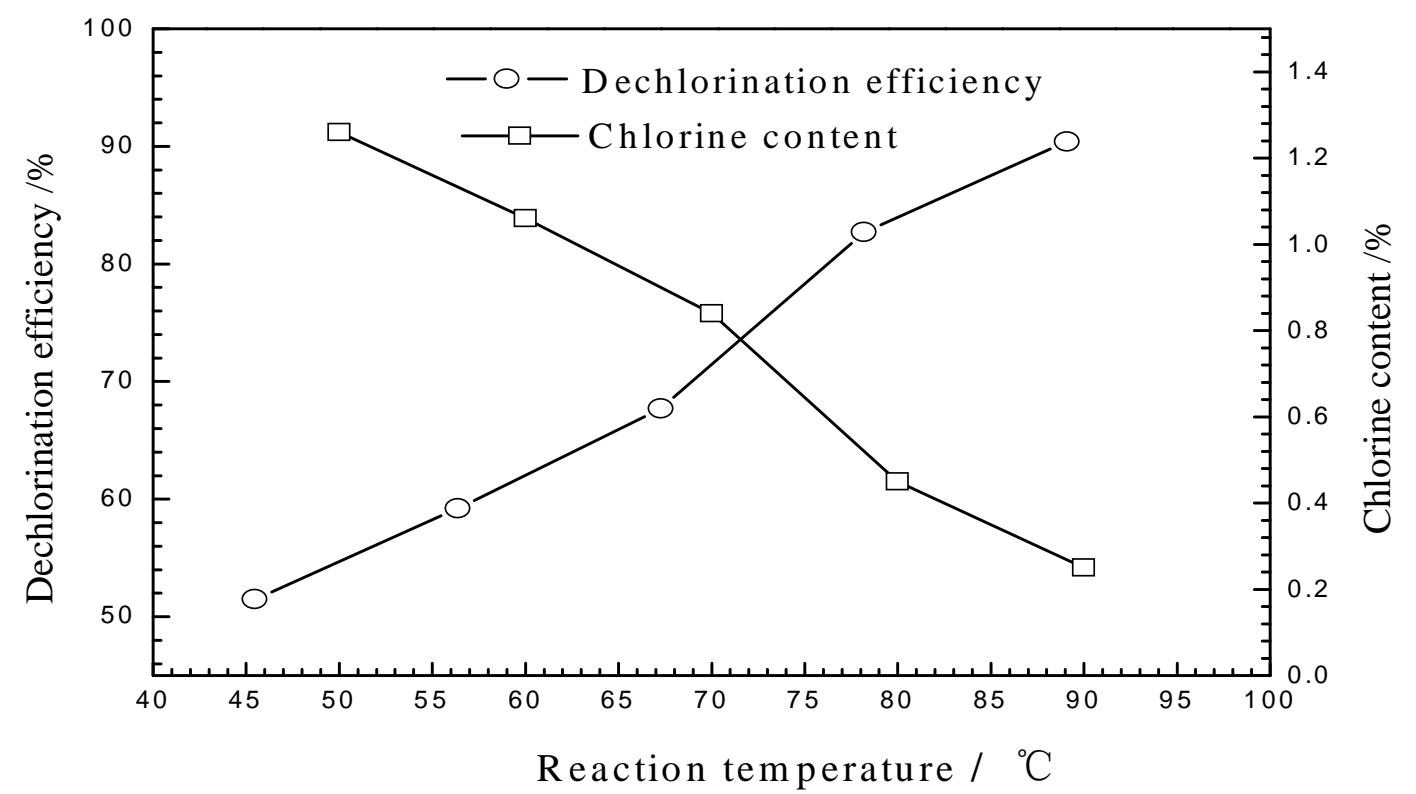

Figure 3: Effects of reaction temperature on chlorine content and dechlorination efficiency

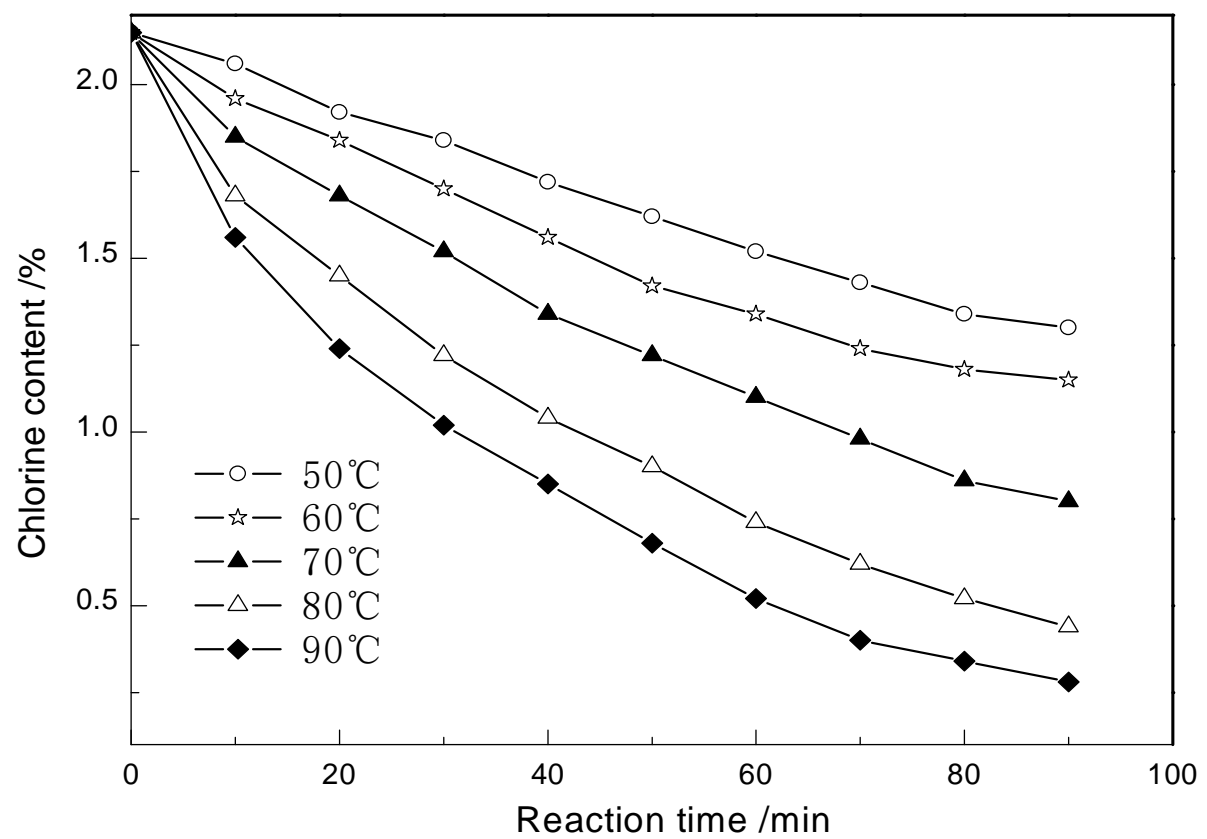

Figure 4: Effect of reaction time on chlorine content 
Figure 4 shows that the chlorine content in the products decreased with the increase of reaction time when chlorine elimination reaction was undertaken at different temperatures.

\section{DISCUSSION}

The $\mathrm{C}-\mathrm{Cl}$ bonds were formed after the $\mathrm{C}=\mathrm{C}$ bonds of shellac molecular structure were added by chlorine during the process that seedlac was bleached with sodium hypochlorite $[24,25]$. As the negative electricity of chlorine atom is bigger than that of carbon atom, the density of electronic cloud of $\mathrm{C}-\mathrm{Cl}$ bonds refuses chlorine atom. Therefore, carbon atom connecting with chlorine has a partial positive charge. With the presence of nucleophilic reagent, the carbon atom binding with chlorine can selectively be attacked, and the chlorine integrated with it can be removed as result of elimination reaction. However, it is not possible for any nucleophilic reagent to effectively eliminate the chlorine combined in the products. At least two factors influence the efficiency of chlorine elimination. One is the active performance of the reagent employed. The other is the features of new products which are formed during the elimination reaction.

Although ethanol is one kind of nucleophilic reagents and also a kind of alkaline agent, its ability for eliminating chlorine is poorer than that of sodium ethoxide. When ethanol was added in the solution to react selectively with $\mathrm{C}-\mathrm{Cl}$ bonds in shellac molecule, the products formed was $\mathrm{HCl}$ which does not easily leave shellac resin and therefore is not good for the elimination of chlorine. On the other hand, by employing sodium ethoxide, the products of elimination reaction was $\mathrm{NaCl}$ which can easily leave shellac resin. Therefore, the chlorine integrated with carbon atom in shellac was eliminated almost thoroughly when sodium ethanol was adopted.

According to the data obtained in the effects of reaction time on the chlorine amount in dechlorination products, the relationship between the natural logarithm value of chorine content and reaction time was sketched in Figure 5 . It demonstrates that the dechlorination reaction belongs to the first order reaction for chlorine content of shellac.

Therefore, the relationship between the natural logarithm value of the reaction constant and the reciprocal of the reaction temperature was expressed as equation (2).

In $\mathrm{k}=12.1756-(4.297 \exp 3) / T, R^{2}=0.9875$.

According to Arrhenius function (equation (3)) and equation (2), the active energy of dechlorination in alkaline shellac solution was carried out as the value of $35.73 \mathrm{~kJ} \cdot \mathrm{mol}^{-1}$, and the reaction constant function at the reaction temperature between 323.15 363.15 $\mathrm{K}$ was expressed as equation (4).

$k=A e^{\left[-E_{a} /(R T)\right]}$

$k=1.940 \exp 5 e^{[-35.73 /(R T)]}$

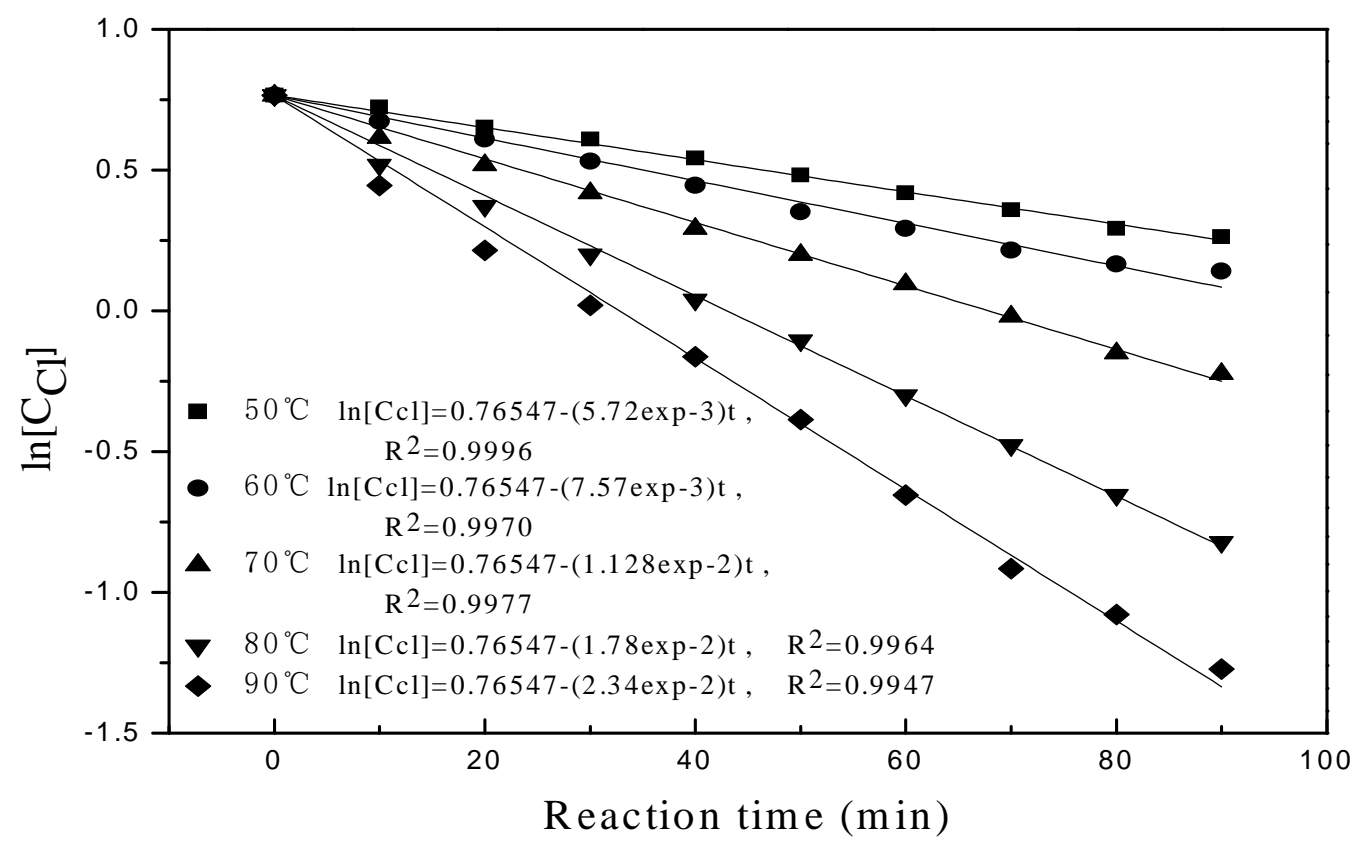

Figure 5: Relationship of $\ln \left[\mathrm{C}_{c l}\right]$ vs reaction time at different reaction temperatures 


\section{CONCLUSION}

Sodium ethoxide is employed as a nucleophilic reagent. When performing elimination reactions, the chlorine integrated in the shellac molecule is eliminated when the agent is put in the bleached solution. The efficiency of chlorine removal is related to the dechlorination agent, reaction time and temperature. The increases in reaction temperature and reaction time are beneficial for chlorine removal. Chlorine content in the products can be decreased to the value below $0.28 \%$ when the reaction is performed for $90 \mathrm{~min}$ at $90{ }^{\circ} \mathrm{C}$.

\section{ACKNOWLEDGEMENT}

This work was financially supported by National Natural Science Fund of China (21266011 and 21566017) and the Pre-investigation Fund jointly provided by Jinchuan Group Co., Ltd and Kunming University of Science \& Technology (no. 4201252011).

\section{REFERENCES}

1. Buch $K$, Penning $M$, Wächterbach $E$, Maskos $M$, Langguth $P$. Investigation of various shellac grades: additional analysis for identity. Drug Dev Ind Pharm 2009; 35: 694-703.

2. Okamoto $M Y$, Ibanez PS. Final report on the safety assessment of shellac. J Am Coll Toxicol 1986; 5 : 309-327.

3. Njombolwana NS, Erasmus A, VanZyl JG, DuPlooy W, Cronje PJR, Fourie PH. Effects of citrus wax coating and brush type on imazalil residueloading, green mould control and fruit quality retention of sweetoranges. Postharvest Biol Tec 2013; 86: 362371.

4. Hagenmaier RD. A comparison of ethane, ethylene and CO2 peel permeance for fruit with different coatings. Postharvest Biol Tec 2005; 37: 56-64.

5. Fallik E, Shalom Y, Alkalai-Tuvia S, Larkov O, Brandeis $E$, Ravid U. External, internal and sensory traits in Galia-type melon treated with different waxes. Postharvest Biol Tec 2005; 36: 69-75.

6. Chitravathi K, Chauhan OP, Raju PS. Postharvest shelflife extension of green chillies (Capsicum annuum L.) using shellac-based edible surface coatings. Postharvest Biol Tec 2014; 92: 146-148.

7. Valencia-Chamorro $S A$, Pérez-Gago MB, Río DMA, Palou L. Curative and preventive activity of hydroxypropyl methylcellulose-lipid edible composite coatings containing antifungal food additives to control citrus post harvest green and blue molds. $J$ Agric Food Chem 2009; 57: 2770-2777.

8. Chauhan OP, Raju PS, Singh A, Bawa AS. Shellac and aloe-gel-based surface coatings for maintaining keeping quality of apple slices. Food Chem 2011; 126 (3): 961-966.

9. Soradech S, Nunthanid J, Limmatvapirat S, Luangtanaanan M. An approach for the enhancement of the mechanical properties and film coating efficiency of shellac by the formation of composite films based on shellac and gelatin. J Food Eng 2012; 108 (1): 94102.

10. Stummer S, Salar-Behzadi S, Unger FM, Oelzant $S$, Penning M, Viernstein H. Application of shellac for the development of probiotic formulations. Food Res Int 2010; 43 (5): 1312-1320.

11. Sauer D, Cerea M, DiNunzio J, McGinity J. Dry powder coating of pharmaceuticals: A review. Int $J$ Pharm 2013; 457 (2): 488-502.

12. Dorożyński $P$, Jamróz $W$, Niwiński K, Kurek M, Węglarz $W$, Jachowicz $R$, Kulinowski $P$. Novel method for screening of enteric film coatings properties with magnetic resonance imaging. Int J Pharm 2013; 456 (2): 569-571.

13. Nadian A, Lindblom L. Studies on the development of a microencapsulated delivery system for norbormide, a species-specific acute rodenticide. Int J Pharm 2002; 242(1-2): 63-68.

14. Pearnchob N, Bodmeier R. Dry polymer powder coating and comparison with conventional liquid-based coatings for Eudragit RS, ethylcellulose and shellac. Eur J Pharm Biopharm 2003; 56(3): 363-369.

15. Farag $Y$, Leopold CS. Development of shellac-coated sustained release pellet formulations. Eur $\mathrm{J}$ Pharm Sci 2011; 42(4): 400-405.

16. Limmatvapirat $S$, Limmatvapirat $C$, Puttipipatkhachorn $S$, Nunthanid J, Luangtana-anan $M$, Sriamornsak $P$. Modulation of drug release kinetics of shellac-based matrix tablets by in-situ polymerization through annealing process. Eur J Pharm Biopharm 2008; 69 (3): 1004-1013.

17. Limmatvapirat S, Panchapornpon D, Limmatvapirat $C$, Nunthanid J, Luangtana-Anan M, Puttipipatkhachorn S. Formation of shellac succinate having improved enteric film properties through dry media reaction. Eur J Pharm Biopharm 2008; 70(1): 335-344.

18. Liao YL, Zhou J, Huang FR, Li BJ. Effects of combined chlorine on physicochemical properties and structure of shellac. Pak J Pharm Sci 2015; 1(Suppl): 329-334.

19. Liao YL, Peng JH, Liu ZH. National and International Seedlac Processing Development and Its Trend. Scientia Silvae Sinicae 2007; 43: 93-100.

20. Wang DX, Gan QG, Ma WQ. Storage properties of shellac. Chem Ind Forest Prod 1987; 7: 25-31.

21. Liao YL, Chai XJ. Preparation of natural shellac with low chlorine content by catalytic hydrogenation and its structure characterization. Chem Ind Forest Prod 2008; 28: 100- 104.

22. Liao YL, Chai XJ, XU FC. Preparation of low chlorine shellac by catalytic hydrogenation with $P d / C$. Adv Mater Res 2011; 152-153: 372-376.

Trop J Pharm Res, November 2015; 14(11): 1959 
23. Liao YL, Xu FC, Li DB. Preparation of low chlorine shellac from seedlac by dechlorination process using $\mathrm{Pd} / \mathrm{Fe}$ binary metal as catalyst. Adv Mater Res 2009; 79-82: 1879-1882.
24. Ha CY, Wang DX. Storage properties of shellac 2th report. Chem Ind Forest Prod 1987; 7: 32-38.

25. Ha CY, Wang DX. Storage properties of shellac fifth report. Chem Ind Forest Prod 1997; 17: 1-5. 